\title{
Recognition of family physicians as experts rather than gatekeepers requires "cultural shift"
}

— Cite as: CMAJ 2018 April 30;190:E550-1. doi: 10.1503/cmaj.109-5591

Posted on cmajnews.com on Apr. 11, 2018.

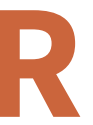

esidency positions for family physicians went unfilled, family doctors were in short supply, and patients or whole communities went without primary care. That was in 2003. There was even a hit Canadian film that year, $L a$ grande séduction, about a Quebec village trying to recruit a family doctor.

"We experienced a nadir in the number of graduating medical students who chose family medicine, at $23 \%$ to $24 \%$," said Dr. Francine Lemire, executive director and CEO of the College of Family Physicians of Canada (CFPC).

Fast forward 15 years and the situation is similar in the United Kingdom, said Dr. Katie Coleman, clinical lead for primary care across north London. She described a "significant shortage" of general practitioners (GPs) in the National Health Service, with numbers declining and rural areas going underserved.

Canada has bolstered students' career choice of family medicine, partly by recognizing family medicine as a specialty in its own right in 2007. Coleman and many others think such recognition would help in the UK as well. The CFPC had the authority to declare family medicine a specialty, but such recognition in the UK must overcome a legislative hurdle. "The Medical Act 1983 has to be changed," said Coleman. "We would have done this several years ago if it wasn't for that."

Coleman started a petition to have general practice so recognized, but she said she will not get the 10000 signatures needed in a six-month period to trigger a mandatory response from the government. However, efforts by other advo- cates, including the Royal College of General Practitioners, will continue.

Does calling family medicine a specialty really make a difference in recruitment of family docs? "I would like to believe that it does," said Dr. Heather Osborn, a specialist in head-and-neck program (two years instead of five), and the physician-patient relationship (having a long-term relationship with patients and providing comprehensive care). But students were drawn to other specialties by factors that included "becoming an expert," "potentially earning a high

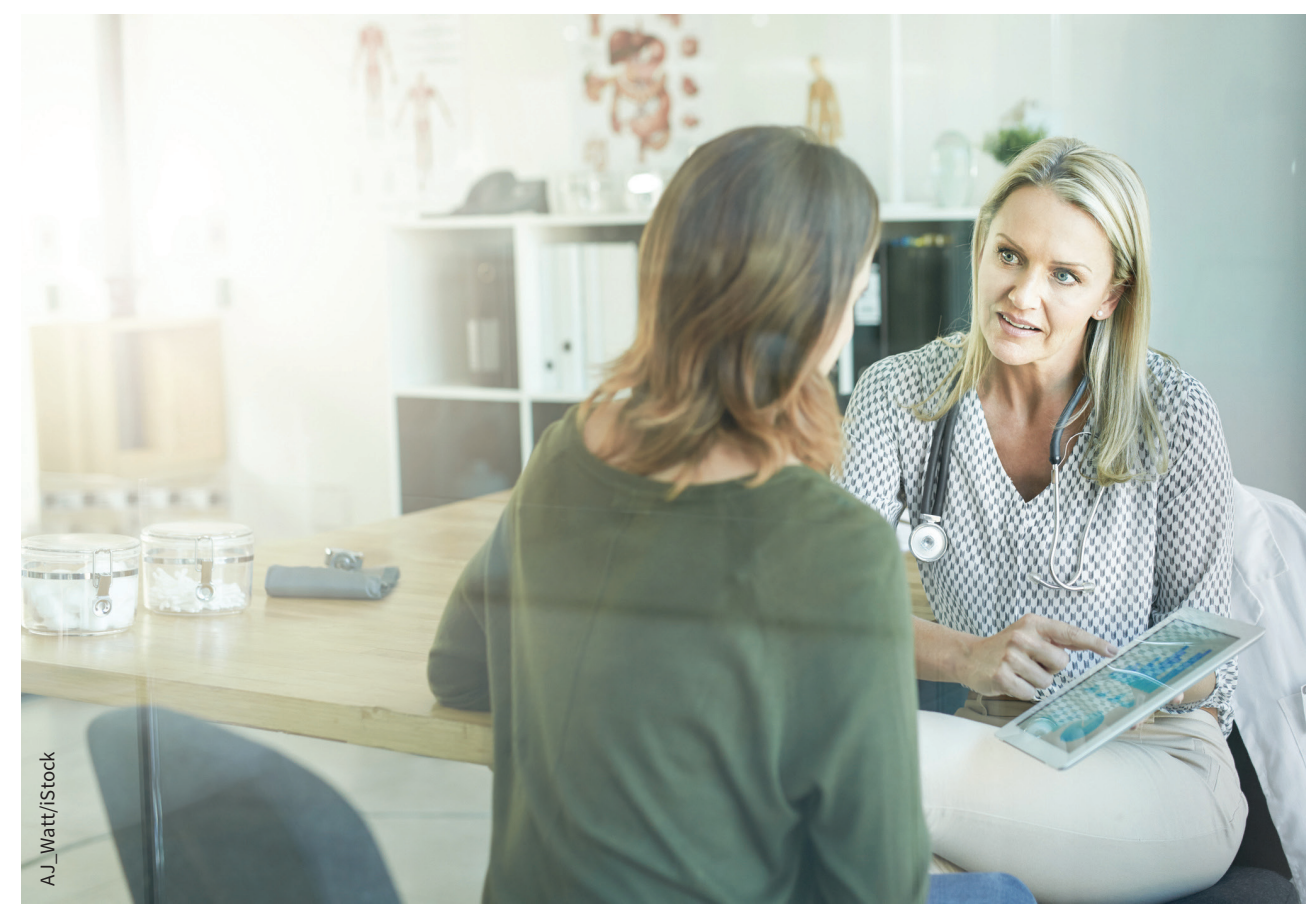

Many family doctors in the UK want their profession recognized as a speciality, as it has been in Canada since 2007.

surgical oncology at Yale University, who conducted a study of factors in residency choice at Western University in London, Ontario.

The study found "three different broad areas that predisposed students to choose primary care," said Osborn. Those areas are work-life balance, duration of income," and "perceived status among colleagues."

Osborn thinks seeing family physicians as high-status experts will require a cultural shift. "That idea of the family practitioner as a gatekeeper who passes on problems to specialists is not the reality any more. Family physicians have a 
spectrum of care that they have a high level of expertise in."

Lemire says that shift has been "a journey," with milestones in 1967 (when the College of General Practitioners of Canada became the College of Family Physicians of Canada), in 1974 (when the first family medicine residencies were instituted), and in the 1990s (when such dedicated training became generally accepted within the profession). In 2007, "we had reached a point in our evolution that there was recognition that family medicine had its own body of knowledge, attitudes and skills, with certification through a summative evaluation. It was appropriate for us to declare family medicine as a specialty."

She credits the change with helping to turn around the dire situation in primary care. "We did subsequently witness a steady increase in the number of graduating medical students who chose family medicine," she said. She believes a recent dip is due to specific issues in certain provinces.

In the UK, however, general practice continues to get a bad rap. A recent report from the Royal College of General Practitioners stated that $76 \%$ of medical students hear disparaging remarks about family medicine from clinicians, educators and academics. The survey of 3680 British medical students also found that $91 \%$ of them believe their peers hold negative attitudes about general practice.

Medical students often ask each other, "What are you going to specialize in or are you just going to be a GP?" said Coleman. "It's a problem getting students to even consider it as a highly respected specialty. It's only when they get a taste of general practice that they see it's a great practice to go into."

Carolyn Brown, Ottawa, Ont. 